\title{
EL POSTHUMANISMO NO ES UN HUMANISMO*
}

\author{
POSTHUMANISM IS NOT AN HUMANISM
}

\author{
Antonio EnRiQue Pérez LuÑo \\ Universidad de Sevilla
}

Fecha de recepción: $15-4-20$

Fecha de aceptación: 29-5-20

Resumen: Este ensayo se propone mostrar la oposición existente entre el paradigma de la tradición cultural humanista y las principales tesis y postulados que actualmente defiende el posthumanismo. Para ello, se analizan las respectivas respuestas que el humanismo y el posthumanismo ofrecen a las tres grandes preguntas que han compendiado, a lo largo de su historia, el significado de la filosofía: ¿Cómo se conoce la realidad? ¿Qué son y cómo se explican el mundo y la vida? ¿Cuál es la mejor forma de vivir? A esas preguntas han respondido respectivamente, la gnoseología o teoría del conocimiento, la ontología y la deontología o la ética. Se estudian, asimismo, determinados motivos de la ambigüedad del proyecto de deshumanización posthumanista. El trabajo concluye con la exposición de los argumentos que avalan la persistencia de los valores, principios y derechos del humanismo, actualizados en función de las exigencias de nuestro tiempo.

Abstract: This paper aims to show the opposition between the Humanist cultural tradition and the main theses currently defended by Posthumanism. The structure of the paper is built upon the corresponding answers provided by both trends to the three main philosophical questions: How do we know reality? What are the world and life, and how are they explained? What is the best way to live one's life? Gnoseology (or theory of knowledge), Ontology, and Deontology or Ethics have respectively tried to provide answers for such questions. Certain ambiguities of the Posthumanist dehumanizing project are also addressed. The paper concludes with an exposition of the arguments that justify the continuity of Humanist values, principles, and rights, updated according to the demands of our time.

* Una versión ampliada de este trabajo se publicará en el número 44 de la revista Doxa.

ISSN: 1133-0937

DERECHOS Y LIBERTADES

DOI: https://doi.org/10.20318/dyl.2021.5848

Número 44, Época II, enero 2021, pp. 17-40 
Palabras clave: humanismo, posthumanismo, dataísmo, deshumanización, sociedad digital, nuevas tecnologías, tecnología de la información y de la comunicación, inteligencia artificial, algoritmos, COVID-19

Key words: humanism, posthumanism, dataism, dehumanization, digital society, new technologies, information and communication technology, artificial intelligence, algorithms, COVID-19

\section{PLANTEAMIENTO}

En el año 1946 Jean-Paul Sartre publicó su célebre ensayo: El existencialismo es un humanismo ${ }^{1}$, obra que junto con la Carta sobre el humanismo de Martin Heidegger de $1947^{2}$, constituyen el manifiesto existencialista sobre la concepción del humanismo. Inspirándome en el título de la obra de Sartre, aunque intencionalidad inversa, propongo designar las reflexiones que prosiguen como: "El posthumanismo no es un humanismo". Mi intención es mostrar, que bajo las propuestas de la ideología posthumanista se encubren determinadas falacias y trampas liberticidas que, entiendo con vehemente convicción, entrañan un riesgo grave para valores de la tradición humanista de persistente e irrenunciable actualidad.

El inicio del nuevo siglo, que coincidió también con el inicio de un nuevo milenio, se ha caracterizado por un protagonismo avasallador de las Nuevas Tecnologías (NT) y de las Tecnologías de la Información y de la Comunicación (TIC), en todos los ámbitos de la vida humana. Este fenómeno ha contribuido a que, desde determinados enfoques tecnocientíficos, se considere que la humanidad actual y sus valores consagrados por el humanismo, deben ser superados, ya que nos hallamos ante los albores de una nueva etapa. Así, James Barrat, sostiene el fin de la era humana y el inicio de una nueva era presidida por la omnipresencia de la inteligencia artificial (IA) ${ }^{3}$. A su vez, Yuval Noah Harari, afirma que se ha superado la era del homo sapiens, que ha sido suplantado por el homo deus ${ }^{4}$, Con las características e implicaciones a las que habrá ocasión de aludir infra.

1 J. P. SARTRE, El existencialismo es un humanismo, trad. cast. de V. Prati, Edhasa, Barcelona, 1992.

2 M. HEIDEGGER, Carta sobre el humanismo, trad. cast. de H. Cortés y A. Leyte, Alianza Editorial, Madrid, 2000.

3 J. BARRAT, Nuestra invención final: La inteligencia artificial y el fin de la Era humana, trad. Cast., de S. Rodríguez, Paidós, México, 2017.

4 Y. N. HARARI, Homo Deus: Breve historia del mañana, trad. cast., R. Joandomènec, Debate, Barcelona, 2016. 
Entre las posturas que invocan hoy la ciencia y la tecnología como marco de referencia para el desarrollo de la vida individual y colectiva, deben distinguirse dos concepciones que obedecen a planteamientos diferentes. Es importante no dejar a la intemperie el respectivo alcance de esas dos concepciones, para evitar que puedan ser entendidas de una forma confusa y arbitraria. De ahí, que sea necesario distinguir netamente entre lo que implica las expresiones "transhumanismo" y "posthumanismo". En numerosas ocasiones, estos términos son asumidos y empleados de forma indistinta, como sinónimos. Ambas expresiones aluden a la reivindicación del derecho a investigar y utilizar, con plena libertad, los avances de la tecnociencia, para conseguir el mayor grado de desarrollo tecnocientífico. Al propio tiempo, estos movimientos se proponen transcender los límites naturales, biológicos o sociales que actualmente condicionan el pleno desarrollo de la existencia. Ahora bien, existe una diferencia básica entre estas dos concepciones. Así, mientras los transhumanistas sostienen que la tecnociencia debe contribuir a la mejora, pero no a la suplantación de la especie humana ${ }^{5}$, los posthumanistas postulan la superación de la humanidad actual por una superhumanidad, como resultado final del proceso de desarrollo tecnocientífico. Para los transhumanistas la tecnociencia debe ser utilizada para una mejora de la calidad de la vida humana. En sus análisis prospectivos se alude reiteradamente a la expresión "humanidad aumentada", para hacer referencia a aquellos progresos y desarrollos que en la condición humana pueden promover las NT y las TIC cuando se hace un uso adecuado de ellas. El transhumanismo no se propone, por tanto, la abolición de cuanto ha supuesto la cultura humanista. El posthumanismo implica la versión "fuerte" de esas proyecciones tecnocientíficas al ámbito de lo humano y, desde sus enfoques, no se duda en postular la sustitución del paradigma humanista por el paradigma posthumanista. De ello, infieren que nos hallamos ante el final de la era humana y la consiguiente aparición de una nueva forma de existencia: la posthumanidad.

En las reflexiones que siguen me ocuparé de esta última concepción e intentaré mostrar las falacias y trampas liberticidas que subyacen a su designio de abolir la tradición del humanismo. Plantear la contraposición entre humanismo y posthumanismo resulta hoy una tarea urgente y perentoria, cuando la entera población del mundo global que habitamos ha visto como se desmoronaba, de manera inimaginable y repentina, su convicción

5 Vid., por todos, F. LLANO ALONSO, Homo excelsior. Los límites ético-jurídicos del transhumanismo, Tirant lo Blanch, Valencia, 2018.

ISSN: 1133-0937

DERECHOS Y LIBERTADES

DOI: https://doi.org/10.20318/dyl.2021.5848

Número 44, Época II, enero 2021, pp. 17-40 
de seguridad existencial, a salvo de cualquier contingencia o imprevisto. El COVID-19 con sus devastadoras consecuencias sanitarias, sociales, económicas y políticas, ha abierto una brecha en la conciencia colectiva y ahora los miembros de la sociedad digital reclaman de la comunidad científica una evaluación objetiva y serena de esta crisis planetaria. Ante esas circunstancias parece no sólo oportuno, sino obligado, someter determinados postulados y previsiones posthumanistas sobre el mundo futuro a la criba crítica de la razón humanista.

\section{APROXIMACIÓN AL HUMANISMO: MOMENTOS DE UNA SÍNTESIS DIACRÓNICA}

Para comprender los términos de la oposición posthumanista al humanismo, conviene tener presente algunos aspectos básicos que conforman el sentido del humanismo. En aras de ello, aludiré, con la máxima voluntad de concisión, a algunos de los momentos de la trayectoria humanista que revisten mayor interés para el propósito de este ensayo.

La tradición humanista occidental ahonda sus raíces en la cultura griega. A tenor de la cualificada opinión de Erik Wolf, puede situarse la génesis de la consciencia humanista en la célebre máxima del sofista Protágoras: “el hombre es la medida de todas las cosas", es decir, que el ser humano es el centro de imputación de todos los procesos del mundo físico y de la realidad social ${ }^{6}$. Con ese postulado se producía, al propio tiempo, la decantación del pensamiento griego clásico desde la etapa cosmológica a la antropológica.

El ideario humanista hallará eco en algunos Diálogos platónicos y en la doctrina ético-jurídica y política de Aristóteles. Su impulso decisivo se manifestará en el seno de la corriente filosófica greco-romana del estoicismo. Será, precisamente, un estoico romano nacido en Córdoba, Lucio Anneo Séneca quien con su sentencia: "homo homini sacra res" 7 , compendiará y proclamará el sentido de la dignidad humana desde los inicios de la tradición humanista occidental.

El humanismo alcanza su plena consagración, y su propia denominación, en el Bajo Medievo y constituirá uno de los ingredientes básicos con18 ss.

E. WOLF, Griechisches Rechtsdenken, Klostermann, Frankfurt, a M., 1952, vol., II, pp.

7 L. A. SÉNECA, Epístolas morales a Lucilio, libro XV, epist., 95, 33. Gregorio PecesBarba, Rector-Fundador de la Universidad Carlos III de Madrid, tuvo el acierto de proponer este lema de Séneca como símbolo emblemático de dicha Universidad. 
formadores de la cultura renacentista. Luego, en el siglo XVIII en el seno del proyecto ilustrado de la Modernidad, se producirá lo que, entiendo, que pudiera denominarse como: "institucionalización del humanismo". En esta etapa es cuando puede hablarse, con propiedad, de la aparición de los derechos humanos como categoría histórica ${ }^{8}$ y se forja también la doctrina jurídico-política del constitucionalismo. Estas categorías darán origen y vertebrarán el Estado de Derecho, en cuyo seno los valores, principios y derechos forjados en la tradición humanista hallarán su plena institucionalización, es decir, su reconocimiento a través de un pertinente marco jurídico-político institucional.

El Estado de Derecho, en su prístina formulación liberal, será objeto de desarrollos y de críticas a lo largo del siglo XIX. En ese periodo, el humanismo ilustrado sufrirá también la descalificación de sus valores, desde algunas tendencias filosóficas y, en particular, será objeto de la implacable crítica de Friedrich Nietzsche.

En el siglo XX el Estado de Derecho será objeto de un ataque frontal por parte de los sistemas políticos totalitarios. Por eso, al finalizar la Segunda Guerra Mundial y para evitar la repetición de una catástrofe humanitaria como la que supuso ese trágico episodio bélico, se produjo una reivindicación de los valores humanistas a escala planetaria. La promulgación en París en el año 1948 de la Declaración universal de los derechos humanos, por parte de Naciones Unidas puede considerarse como la Carta Magna del humanismo contemporáneo y la consiguiente revalorización y actualización del legado de la cultura humanista ${ }^{9}$. En dicho texto se recogen los principales valores, principios y derechos del humanismo y constituyen el paradigma, para la fundamentación y la crítica, de las concepciones y de los sistemas jurídico-políticos de nuestro tiempo. Este importante logro humanista no implica el que los valores y derechos de la Declaración universal hayan adquirido vigencia en todos los ámbitos de nuestro planeta. En la actualidad, aunque de vergüenza reconocerlo, para millones de habitantes de nuestro mundo, la Declaración universal sigue siendo una promesa incumplida. De ahí, el peligro que subyace a aquellas pretensiones tendentes a considerar al humanismo como una experiencia conclusa, que debe ser superada.

8 G. PECES-BARBA, Tránsito a la Modernidad y derechos fundamentales, Eudema, Madrid, 1988.

9 A. E. PÉREZ LUÑO, Derechos humanos, Estado de Derecho y Constitución, Tecnos, Madrid, $12^{\text {a }}$ ed, 2017, pp. 79 ss. 


\section{MOMENTOS DE LA OPOSICIÓN ENTRE EL HUMANISMO Y EL POSTHUMANISMO}

Para calibrar el significado y alcance de la contraposición entre humanismo y posthumanismo conviene, por razones de orden sistemático, analizar la respuesta que cada una de estas dos concepciones aportan a las tres grandes preguntas que han compendiado, a lo largo de su historia, el significado de la filosofía: ¿Cómo se conoce la realidad? ¿Qué son y cómo se explican el mundo y la vida? ¿Cuál es la mejor forma de vivir? A esas preguntas han respondido respectivamente, la gnoseología (la teoría del conocimiento, la epistemología, la lógica, la metodología...), la ontología y la deontología o la ética.

a) A la primera de esas preguntas, es decir, a la demanda gnoseológica, el humanismo ha respondido en términos de razón y de experiencia. Las diversas escuelas y movimientos filosóficos han puesto el énfasis en cada una de estas categorías a tenor de sus peculiares enfoques filosóficos. Las distintas posiciones filosóficas, desde las que el humanismo ha sido postulado, coinciden en sustentar que el conocimiento que transciende o se sitúa más allá de la razón y/o de la experiencia humana, pertenece al ámbito de lo metafísico, lo irracional o lo fantástico.

En consonancia con tal planteamiento y corroborándolo, conviene recordar que el más célebre representante del irracionalismo del siglo XIX, Friedrich Nietzsche, se opuso a la tradición humanista y, en particular, a su versión ilustrada, al considerar este tipo de conocimiento como "humano, demasiado humano" (Menschliches, Allzumenschliches) ${ }^{10}$.

En la actualidad, el posthumanismo, desde una perspectiva que pretende ser antagónica a la de Nietzsche, coincide con él en su designio de superar el humanismo. Lo hace desde premisas inversas al carácter especulativo y a la "ensoñación" de las fabulaciones irracionales del filósofo germano, para invocar el rigor estricto de una reflexión tecnocientífica. Ejemplo elocuente de la actitud posthumanista es la propuesta de James Barrat de suplantar la fragilidad del conocimiento humano gracias al empleo de la IA. Según Barrat el conocimiento racional y empírico, propio de los seres humanos es de carácter limitado, fragmentario y falible. Mientras

10 F. NIETZSCHE, Humano, demasiado humano, trad. cast, P. Simón, Prestigio, Buenos Aires, 1970. 
que el conocimiento que propicia la IA es ilimitado, omnicomprensivo e infalible ${ }^{11}$.

El fenómeno del Big-Data permite un almacenamiento prácticamente ilimitado de informaciones, las cuales pueden ser procesadas y utilizadas en los más diversos ámbitos y para las más diversas finalidades ${ }^{12}$. Todo ello, permite un avance del conocimiento de datos cuya entidad cuantitativa, en opinión de los posthumanistas, conduce a una nueva situación cualitativa en cuanto respecta al conocimiento de la realidad. Acorde con la célebre ley del método dialéctico que postula el paso de la cantidad a la calidad, la actitud posthumanista no duda en afirmar que nos hallamos ante un conocimiento cualitativamente distinto y superior al modus cognoscendi del pasado, gracias a las aportaciones de la IA.

b) En el plano ontológico, el humanismo ha explicado el ser y el tiempo a través de la comprensión racional y/o empírica de la realidad, propiciando una indagación del ser que condujera a entender y posibilitar su pleno desarrollo. En particular, su empeño se cifró en contribuir al logro de la plenitud de la persona humana. Conviene al respecto tener presente, que en algunos Diálogos de Platón se reitera el término pleonexia, que evoca la idea de un desarrollo pleno de las facultades, apetitos y tendencias de los seres humanos. En opinión de Erik Wolf, esta categoría platónica pudo hallarse inspirada en la notoria máxima del poeta Píndaro: "llega a ser el que eres" es decir, la exigencia de que cada sujeto desarrolle plenamente el proyecto existencial que se encierra en el interior de su personalidad ${ }^{13}$.

11 J. BARRAT, Nuestra invención final: La inteligencia artificial y el fin de la Era humana, cit., pp. 49 ss. y 126 ss.

12 Cfr., A. GARRIGA DOMÍNGUEZ, Nuevos retos para la protección de datos personales. En la Era del Big Data y de la computación ubicua, Dykinson, Madrid, 2015.

13 E.WOLF, Griechisches Rechtsdenken, cit., pp. 172 ss. La concepción platónica de la pleonexia constituye un factor hermenéutico relevante para una reinterpretación de las tesis que le consideraban como un pensador totalitario y enemigo de la sociedad abierta (Karl Popper). Esta categoría permite inscribir la concepción política de Platón en la esfera del personalismo, ya que considera que el fin de la comunidad política ideal es la consecución del pleno desarrollo de la personalidad humana. El método para conseguirlo suscita serias reservas, por ser antidemocrático, pero la finalidad de su ideal político no es transpersonalista, sino inequívocamente personalista. Esta reinterpretación del pensamiento jurídico-político platónico posibilita concebirlo como un precedente histórico del personalismo que fundamenta los Estados de Derecho del presente. Así la Constitución alemana proclama en su art. 2.1 "el libre desarrollo de la personalidad", y, asimismo, el art. 10.1 de la Constitución española establece 
Frente a esa concepción ontológica humanista opuso Friedrich Nietzsche la tesis de que la humanidad no constituye una meta, sino sólo un estadio en la trayectoria hacia la superhumanidad. Ha adquirido celebridad su leitmotiv presente a lo largo de su obra Así habló Zaratustra, a tenor del cual, el hombre es la cuerda tendida entre la bestia y el superhombre ${ }^{14}$.

Una visión semejante en lo que respecta a la necesidad de superar las limitaciones de la realidad ontológica humana, aunque desde un planteamiento que pretende rechazar toda concesión al irracionalismo y situarse en un plano tecnocientífico, es la que hoy postulan los ideólogos posthumanistas. Así, Yuval Noah Harari, al hacerse eco del ideario de ese movimiento, sostiene que, gracias a los avances tecnológicos y biocientíficos, hoy nos hallamos ante una nueva dimensión de la existencia humana. La IA permite un conocimiento sin trabas de cuanto existe. Como todo conocimiento es poder, los seres posthumanos estarán dotados de unas posibilidades ilimitadas de actuación sobre el mundo y la vida. La muerte, tradicionalmente considerada como un fenómeno metafísico vinculado a la voluntad de unos presuntos designios divinos, será entendida como un mero problema técnico y podrá ser resuelta con medios técnicos. De este modo, la ingeniería genética y las biotecnologías permitirán una prolongación indefinida de la vida humana. Concluye Harari que durante milenios, los dioses se caracterizaban por poseer la omnisciencia, la omnipotencia y la eternidad y, precisamente, esos atributos podrán ser disfrutados por los posthumano: el homo sapiens será sustituido por el homo Deus ${ }^{15}$.

No parece ocioso aludir también a otras proyecciones de la propuesta posthumanista en la esfera ontológica. Entre ellas, posee una trascendencia especial la hipótesis que aventura sustituir las formas de vida orgánica basadas en el carbono, por formas de vida inorgánica basadas en el silicio, lo que permitiría una prolongación sustancial de las formas de vida. No menos con-

"el pleno desarrollo de la personalidad"; hallándose ambos textos normativos en el frontispicio de sus respectivos catálogos de los derechos fundamentales. Otro aspecto importante que se desprende de la concepción platónica de la pleonexia, estriba en su virtualidad para una superación de la tesis que postula la imposibilidad de derivar el "deber ser" a partir del "ser". Se ha hecho notoria esta tesis planteada por David Hume y, en la filosofía contemporánea, bajo la denominación de "naturalistic fallacy", a través de George Edward Moore. Frente a esa fractura, la enseñanza platónica muestra que el desarrollo del "ser" tiende a perfeccionarse y alcanzar su plenitud, en el "deber ser".

14 F. NIETZSCHE, Así habló Zaratustra, trad, cast, de A. Sánchez Pascual, Alianza Editorial, Madrid, 1972.

15 Y. N. HARARI, Homo Deus: Breve historia del mañana, cit., pp. 323 ss.

DERECHOS Y LIBERTADES

Número 44, Época II, enero 2021, pp. 17-40
ISSN: 1133-0937

DOI: https://doi.org/10.20318/dyl.2021.5848 
secuencias poseen las investigaciones en materia de nanotecnologías, que han recibido un impulso decisivo a partir de los estudios de Manfred Clain y Natham Klein, es decir, la posibilidad de manipular la materia para su transformación o eventual elaboración de nuevas formas materiales. Asimismo, deben reseñarse los importantes avances en la robótica y en la tecnología de cyborgs, que consiste en la posibilidad de proyectar dispositivos cibernéticos en organismos biológicos para una superación cualitativa de las capacidades de éstos mediante la tecnociencia. Se abre así la posibilidad de transferir formas de IA a animales o a seres humanos y viceversa de transplantar segmentos o circuitos del cerebro humano a máquinas ${ }^{16}$.

A partir de estos enfoques y propuestas, los posthumanistas vislumbran un futuro en el que la realidad social ya no estará sometida a la maldición bíblica que pesa sobre los seres humanos de tener que ganar su sustento mediante el trabajo. El desarrollo de la robótica permitirá sustituir el esfuerzo humano por la actividad de la máquina y, de este modo, los posthumanos podrán emanciparse de esa servidumbre y podrán gozar de todo su tiempo para disfrutar del ocio, de las artes y del deporte ${ }^{17}$.

c) En el plano ético el humanismo ha defendido siempre aquellos valores más intrínsecamente ligados con la personalidad humana. Dichos valores, a partir de la Ilustración y del movimiento constitucionalista, se consagran en los derechos y libertades legitimadores de los Estados de Derecho. La tradición humanista, como se ha indicado supra, consagrará sus valores, principios y derechos en las normas constitucionales que se hallan en la cúspide de los Estados de Derecho. A partir de la Revolución francesa, dichos valores se expresarán mediante los símbolos de la tricolor: libertad, igualdad y fraternidad, que junto con la dignidad constituyen la síntesis axiológica del humanismo.

También en este ámbito Friedrich Nietzsche se mostrará abiertamente crítico respecto a la cultura humanista y, en particular, a su versión raciona-

16 Sobre todo ello, vid.: M. BARRIO, "Robots, inteligencia artificial y persona electrónica", en el vol., col., a cargo de T. de la Quadra-Salcedo y J.L.Piñar, Sociedad digital y Derecho, BOE, Madrid, 2018, pp. 113 ss.; F. FUKUYAMA, El fin del hombre: consecuencias de la revolución biotecnológica, trad. cast. de, P.Reina, Ediciones B, Barcelona, 2002, pp 289 ss.; J. HABERMAS, El futuro de la naturaleza humana ¿Hacia una eugenesia liberal? trad., cast. R. Carbó, Paidos, Barcelona, 2016, pp. 83 ss.; T. de la QUADRA-SALCEDO, "Retos, riesgos y oportunidades de la sociedad digital", en el vol. Col., en Sociedad digital y Derecho, cit., pp. 21 ss.

17 Cfr., J. BARRAT, Nuestra invención final: La inteligencia artificial y el fin de la Era humana, cit., pp. 85 ss. 
lista ilustrada, al sustentar que la libertad la dignidad y la igualdad eran falsos valores, propios de seres débiles y mezquinos que serían superados por la voluntad de poder del superhombre. La igualdad le parece algo propio de seres inferiores, que se conforman con la existencia gregaria de los integrantes de un rebaño. Por el contrario, al superhombre le repugna la igualdad, porque desea ser desigual y superior a los otros ${ }^{18}$.

Hoy el posthumanismo replantea esa transmutación de los valores desde un enfoque tecnocientífico. Su crítica a los valores humanistas se plantea como una alternativa frontal respecto a esa concepción. Desde el enfoque posthumanista se niega, abiertamente, la existencia del libre albedrio y, por tanto, la posibilidad de un ejercicio autónomo e incondicionado de la libertad de elección y decisión. De ahí, que la libertad que actualmente importa no es tanto la que atañe a los derechos o facultades de los individuos, sino que pone el énfasis en la libre investigación científica, sin límites o tabúes que puedan impedir su pleno ejercicio. Desde la ideología posthumanista se entiende cualquier restricción moral o legal a la libre investigación y experimentación como un símbolo anacrónico de oscurantismo. De igual forma que los Reformadores protestantes invocaban el libre examen, como principal garantía de la libertad de la conciencia, los posthumanistas defienden el libre ejercicio de la investigación y la experimentación tecnológica y científica, como la forma más representativa de la libertad en el presente. Para los posthumanistas, en definitiva, las normas éticas, jurídicas o políticas que representen una cortapisa al desarrollo tecnológico o científico, son trabas incompatibles con los avances que reclama el progreso. Por tal motivo, en fecha muy reciente, desde diferentes foros afines al posthumanismo, se ha considerado, como una victoria relevante, que la legislación japonesa haya permitido que el profesor de la Universidad de Tokio Hiromitsu Nakauchi, experto en biotecnología lleve a cabo experiencias de humo-animales, que consisten en la implantación de células humanas en embriones de animales. Así, se pretende la producción de órganos susceptibles de ser transplantados a seres humanos. La posibilidad de seres híbridos, mezcla de elementos humanos y animales, que hasta el presente se hallaba en la esfera mitológica de los faunos, centauros, sirenas, esfinges..., puede llegar a ser una realidad futura.

18 F. NIETZSCHE, Más allá del bien y del mal, trad, cast., A. Sánchez Pascual, Alianza Editorial, Madrid, 1972, pp. 116 ss.; La voluntad de poder. Ensayo de una transmutación de todos los valores, trad. cast., P. Simón, Editorial Prestigio, Buenos Aires, 1970, pp. 46 ss.

DERECHOS Y LIBERTADES

ISSN: 1133-0937

Número 44, Época II, enero 2021, pp. 17-40

DOI: https://doi.org/10.20318/dyl.2021.5848 
Desde premisas posthumanistas se sostiene que el futuro sentido de la libertad política no dependerá de las deliberaciones de los Parlamentos democráticos o de los foros internacionales, que siempre pueden estar sujetas a su contaminación por pasiones o intereses. La política del futuro será el producto de decisiones inteligentes y asépticas tales como los resultados de la investigación que tiene lugar en los laboratorios de Silicon Valley de California ${ }^{19}$. De esta forma, los aspectos más decisivos sobre el porvenir de la especie no obedecerán a procesos de selección natural, sino a una programación inteligente.

Critican también los posthumanistas el valor de la igualdad, proclamado por el humanismo, por su carácter insuficiente y, en definitiva, injusto. En el Estado de Derecho liberal se pretende garantizar la igualdad jurídica de los ciudadanos, en términos de igualdad ante la ley. A su vez, el Estado social de Derecho se propone garantizar determinadas cuotas de bienestar, a partir del reconocimiento de la igualdad material. Los posthumanistas denuncian que estas formas de igualdad son insuficientes, ya que no tienen en cuenta las inmensas desigualdades existentes entre las facultades físicas e intelectuales de las personas. Sólo una insignificante minoría de personas puede participar en las Olimpiadas, u optar al Premio Nobel. Según los posthumanistas la experimentación sin trabas de la ingeniería genética, de las biotecnologías y de la neurociencia, hará posible imaginar a seres posthumanos, cuyas capacidades físicas e intelectuales posean un nivel mucho más equilibrado de igualdad.

La descalificación posthumanista de los valores jurídico-políticos del humanismo, se dirige también a denunciar su fracaso en el diseño de sociedades bien ordenadas. Hasta el presente las sociedades democráticas no han podido erradicar de su seno las conductas desviadas delictivas o antisociales, que entrañan un peligro para el orden y, en ocasiones, para la propia pervivencia de la comunidad política. Estas graves insuficiencias de las sociedades actuales podrán ser corregidas mediante el empleo de técnicas neurológicas que erradiquen de los cerebros las actitudes antisociales y que permitan establecer un orden social plenamente justo, en el que no exista la lacra endémica de la delincuencia.

19 Cfr., J. BARRAT, Nuestra invención final: La inteligencia artificial y el fin de la Era humana, cit., pp. 183 ss.; Y. N. HARARI, Homo Deus: Breve historia del mañana, cit., pp. 294 ss. 


\section{LAS FALACIAS POSTHUMANISTAS}

Para quienes, como es mi caso, no compartimos el ideario posthumanista, sus propuestas deben ser sometidas a una revisión crítica que tienda a poner de manifiesto las insuficiencias y falacias sobre las que se construye su desafío al humanismo. Para ello, mantendré el orden expositivo en el que he cifrado la oposición sistemática entre humanismo y posthumanismo.

a) Desde el punto de vista gnoseológico, es decir, desde la teoría del conocimiento se advierte que el posthumanismo no pretende ofrecer vías de acceso al conocimiento de la realidad, sino que crea una determinada forma de realidad, acorde a sus propios planteamientos. El posthumanismo más que un método de conocimiento, tiende a convertir el método en el propio objeto de conocimiento. Pudiera ejemplificarse ese modus cognoscendi si imaginamos una ventana cuyo cristal nos permite contemplar un determinado paisaje. El cristal es un medio para visualizar, para conocer, el panorama que se halla más allá de la ventana. Nos permite conocer esa realidad sin tener que sufrir las inclemencias del tiempo: lluvia, viento, calor, frío... Cuanto más diáfano sea el cristal, mejor contribuirá a nuestro conocimiento o visión de la realidad, pero si sustituimos el cristal por una lente calidoscópica, podremos obtener una combinación de coloraciones y unas combinaciones cromáticas que podrán gozar de gran plasticidad, en el plano estético, pero que no nos permitirá contemplar la realidad existente fuera de la ventana. El riesgo que se deriva del método cognoscitivo del posthumanismo, reside, precisamente, en que no nos ofrece una visión de la realidad, sino que propone una realidad construida artificialmente, a través de la IA, el Big Data y los algoritmos diseñados para su elaboración.

Yuval Noah Harari ha resumido, de modo inequívoco el alcance de la revolución gnoseológica auspiciada por el posthumanismo: "Gracias a los ordenadores y la bioingeniería, la diferencia entre ficción y realidad se difuminará, a medida que la gente remodele la realidad para que se ajuste a sus ficciones favoritas" 20 .

La teoría del conocimiento que propone el posthumanismo, concluye por ofrecernos una realidad virtual que enmascara la realidad auténtica, propicia una postverdad que supone una mentira con apariencia de verdad.

20 Y. N. HARARI, Homo Deus: Breve historia del mañana, cit., p. 203.

DERECHOS Y LIBERTADES

Número 44, Época II, enero 2021, pp. 17-40
ISSN: 1133-0937

DOI: https://doi.org/10.20318/dyl.2021.5848 
b) La dimensión ontológica del poshumanismo concibe un futuro de seres posthumanos omniscientes, omnipotentes y eternos. Esas perfecciones imaginadas para un mundo futuro han sido abiertamente impugnadas por Stefano Rodotà, figura indiscutible de la cultura jurídica contemporánea. Uno de sus últimos trabajos lleva por significativo título: Del ser humano al posthumano. En dicho estudio denuncia que la lógica desde la cual se sitúan los vaticinios y profecías posthumanistas, no es la del interés y el bienestar de las personas, sino que representa la lógica del beneficio económico. A juicio de Rodotà, de los eventuales beneficios de la revolución posthumanista no gozaría la totalidad de la población mundial. Al realizarse dicha revolución desde parámetros elitistas, es decir, dirigida por una minoría de científicos y tecnólogos, no existirían garantías de que de la misma pudiera beneficiarse la mayoría de la población. Se establecería así una brecha tecnológica entre tecnoricos y tecnopobres. Estos últimos quedarían marginados de los avances del progreso y de las decisiones sobre su propio futuro. La robótica, sino se halla dirigida por valores humanistas y democráticos, corre el riesgo de condenar a ingentes masas de población a convertirse en una muchedumbre inútil para los procesos productivos y la evolución del nuevo sistema, social con el consiguiente riesgo de que ello pudiera conducirla a la miseria o, en el peor de los casos, a su paulatina desaparición ${ }^{21}$.

c) Los posthumanistas piensan que gracias a la robótica las sociedades del futuro quedarán emancipadas de la secular imposición bíblica de ganar el sustento con fatiga. La eliminación de las formas más penosas, arduas y peligrosas de trabajo humano pueden ser sustituidas por la robótica. Ahora bien, la responsabilidad en la dirección y orientación de los robots no puede quedar en manos de tecnólogos o de la IA, porque la organización del trabajo y el empleo del tiempo libre son cuestiones que afectan a la vida de las personas y que, por tanto, no pueden eludir las exigencias y garantías de un orden sociopolítico dirigido por el respeto a los derechos humanos ${ }^{22}$.

d) No resulta menos radical la crítica que, desde el humanismo, se pueden dirigir hacia los presupuestos y consecuencias éticas del posthumanis-

21 S. RODOTÀ, "Del ser humano al posthumano", en el vol., Sociedad digital y Derecho, cit., pp. 87 ss.

22 Sobre todo ello, vid., R. DE ASIS ROIG, Una mirada a la robótica desde los derechos humanos, Dykinson, Madrid, 2015. 
mo. Quizás convenga recordar que, para Kant la dignidad humana se situaba en el reino de los fines y consistía en la exigencia de tratar a todas las personas como fines en sí mismas y no como medios o instrumentos para la consecución de otras metas u objetivos ${ }^{23}$. El posthumanismo, instrumentaliza y mediatiza a las personas en función de un modelo de progreso que no tienen en cuenta sus posibilidades de decisión. La lógica transpersonal de la IA y los algoritmos deciden sobre los fines y objetivos futuros del desarrollo de la vida, al margen de las elecciones de las personas concernidas por esos designios.

La dignidad humana es también el fundamento de la identidad personal, concebida como el derecho de cada ser humano a tener una personalidad única irrepetible y genuina. Para el posthumanismo, ese derecho se basa en una pretensión ilusoria, ya que, como se ha indicado supra, niega la existencia de un yo auténtico e irrepetible por considerar que tal pretensión contradice las leyes de la genética y los desarrollos presentes de las biotecnologías. La posibilidad de proyectar circuitos cerebrales humanos sobre máquinas, es decir, robots, realizable a partir de la ingeniería de Cyborg, permite conectar el pensamiento, la memoria y las experiencias humanas en seres artificiales y multiplicar esos procesos ilimitadamente. Las experiencias de interfaces entre distintas personas, con la correspondiente intercomunicación de ideas, preferencias y exigencias suponen negaciones radicales de un derecho a la identidad, al permitir formas de identidades clonadas o identidades en serie; o lo que es lo mismo, la propia abolición del significado de la identidad.

Una temática, ampliamente debatida en los últimos años es la referente a las amenazas que las pretensiones posthumanistas pueden implicar para la garantía del derecho a la intimidad y a la protección de los datos personales. En esta esfera, el Big Data y los algoritmos representan un riesgo de vaciamiento de las garantías jurídicas establecidas para la defensa de estos derechos ${ }^{24}$. De cumplirse ciertas profecías posthumanistas, cabe conjeturar que la colonización de la vida privada no se limitaría a las situaciones pasadas y presentes, sino que podría perpetrarse en invasiones de nuestra intimidad futura. Se aventura, desde esas premisas posthumanistas, la inquietante

23 Cfr., A.E. PÉREZ LUÑO, “Kant y los derechos humanos”, en su vol, La Filosofía del Derecho en perspectiva histórica, Servicio de Publicaciones de la Universidad de Sevilla, Sevilla, 2009, pp. 117 ss.

${ }_{24}$ Cfr., A. GARRIGA DOMÍNGUEZ, Nuevos retos para la protección de datos personales. En la Era del Big Data y de la computación ubicua, cit. passim.; A.E. PÉREZ LUÑO, Derechos humanos, Estado de Derecho y Constitución, cit., pp. 351 ss. 
posibilidad de que los datos masivos almacenados sobre todos los aspectos de nuestra vida, una vez elaborados por los algoritmos, permitieran predecir con exactitud cuál iba a ser nuestro voto en los próximos comicios políticos, nuestras preferencias comerciales y nuestra elección sentimental.

Por tal motivo la teoría de los derechos y libertades tiene que precaverse ante esos eventuales y ominosos riesgos ${ }^{25}$. El derecho a la libertad y, en concreto el derecho a la libertad política de los ciudadanos, es considerado por el posthumanismo como una pretensión ilusoria. Ese postulado es fruto de su negación absoluta del libre albedrío, al que consideran fruto de una ensoñación metafísica, ya que la tecnobiología y la neurociencia, muestran que cualquier decisión humana es el producto de la carga genética, de determinados rasgos de los circuitos cerebrales o de respuestas necesarias de la mente ante ciertas situaciones ambientales.

De cumplirse las inquietantes profecías posthumanistas, nos hallaríamos ante el final de la libertad en el espacio público. Pero, ese diagnóstico, no tiene por qué ser irrefutable y la mejor forma de defender los derechos humanos consiste en reforzarlos ${ }^{26}$. Como todo avance científico y tecnológico las NT y las TIC poseen una dimensión ambivalente y es posible revertir su amenaza liberticida, mediante una utilización racional y democrática, acorde con los valores humanistas, que aproveche los aspectos positivos que ofrece el progreso en la sociedad digital para reforzar la libre participación política a través de nuevas formas de ciberciudadanía ${ }^{27}$.

La autonomía de las personas queda suplantada, en el proyecto posthumanista, por la autonomía de los sistemas, la autonomía de los vehículos, la autonomía en los procesos de producción y reproducción de cosas... Asimismo, Internet que ha sido concebida como un espacio para el ejercicio libre de las actividades personales, es decir, como Internet de las personas, pierde protagonismo en favor de la Internet de las cosas.

25 Cfr., A.E. PÉREZ LUÑO, “Las generaciones de derechos humanos ante el desafío posthumanista”, en el vol., col., a cargo de T. de la Quadra-Salcedo y J. L. Piñar Mañas, Sociedad Digital y Derecho, cit., pp.137 ss.

26 F. J. ANSUATEGUI, "Nuove tecnologie e spazio pubblico". Texto que se halla en curso de publicación y que debo a la deferencia de su Autor.

${ }_{27}$ Cfr., F. J. ANSUATEGUI, "Nuove tecnologie e spazio pubblico", cit.; A.E. PÉREZ LUÑO, ¿Ciberciudadani@ o ciudadani@com?, Gedisa, Barcelona, 2004, pp. 72 ss.; Id., Construcción Europea y Teledemocracia (con la colaboración de: F. de Carreras, T. Limberger, R. González-Tablas), Fundación Coloquio Jurídico Europeo, Madrid, 2013, pp.13 ss. y 117 ss. 
Las grandes decisiones políticas y sociales sobre la sanidad, educación, seguridad, empleo, medio ambiente... Quedan sustraídas al debate democrático público y se confían a gabinetes tecnocráticos que toman decisiones fundadas únicamente en los procesamientos de datos que a partir del Big Data elaboran los algoritmos. La culminación de este proceso, a tenor de la lógica dataista del posthumanismo, desembocaría en la plena sustitución de las decisiones humanas por la IA, que estaría en condiciones de proporcionar, en cada caso, la solución correcta. Como es obvio, esta lúgubre posibilidad implicaría la disolución de toda forma de responsabilidad política, con las perversas consecuencias que ello entrañaría para la subsistencia de una convivencia en libertad.

En las previsiones sobre el futuro de la sociedad, avanzadas por los posthumanistas, se augura la plena superación de las desigualdades físicas y mentales entre todas las personas. Vislumbran, a la vez, sociedades en las que se podrá abolir toda forma de delincuencia, a través de programaciones de la conducta. De cumplirse esa pretensión posthumanista, nociones tales como las de responsabilidad, culpa, dolo, negligencia, buena fe..., dejarían de formar parte del catálogo de conceptos jurídicos fundamentales, porque se habría suprimido el propio valor de la libertad personal, que es presupuesto necesario de todas esas categorías. La sociedad futura, auspiciada por los posthumanistas, estimo, que más que un sueño confortador de una convivencia libre, armónica y bien ordenada, se asemeja a la pesadilla de ese Mundo Feliz imaginado, genialmente, por Aldous Huxley, o al del modelo opresivo de organización política presidido por la sombra despótica del gran Hermano, según la anti-utopía descrita por George Orwell en su célebre obra 1984.

\section{LA DESHUMANIZACIÓN POSTHUMANISTA: SU AMBIGÜEDAD}

De cuanto hasta aquí se lleva expuesto, es fácil inferir que la actitud posthumanista entraña un decidido propósito de sustituir el paradigma antropocéntrico del humanismo por el paradigma tecnocéntrico. A tenor de ese designio se estaría produciendo, en el presente y en el inmediato futuro, un proceso de paulatina deshumanización de las sociedades y de la cultura, al que correlativamente serviría de fundamento legitimador una ideología suprahumanista. Tal como se ha tenido ocasión de advertir al exponer la contradicción entre humanismo y posthumanismo, en el plano ético, esta última 
ideología lleva implícita la pretensión de subvertir o superar los valores propios de la tradición humanista.

Al iniciar esta exposición traté de esbozar una síntesis de cuanto ha supuesto la cultura humanista en la trayectoria histórica de Occidente. Para el humanismo, la humanidad representa siempre una categoría axiológica, un bien que debe ser preservado y desarrollado. En contra de esta pretensión se alza la tesis posthumanista, que entiende que la humanidad no representa el fin de la historia, sino una mera etapa en su desarrollo, que puede y debe ser superada por el ideal de la superhumanidad, a partir de un proceso de progresiva deshumanización.

En los últimos años ha aparecido una extensa bibliografía, integrada por ensayos y diagnósticos, relativos a la deshumanización tecnocientífica de la sociedad y la cultura. Algunas de estas proclamas constituyen un lamentable paradigma de confusión, que delata la forma apresurada e imprecisa con la que han sido elaboradas. En múltiples ocasiones, son sus autores audaces sprinters encaramados en marcha en el tren de las NT y las TIC, sin saber de donde viene y adonde va. En aras de mayor rigor en el estudio de esta materia parece oportuno, para aclarar de qué estamos hablando cuando nos referimos a la "deshumanización", al planteamiento de ese concepto por parte de José Ortega y Gasset. A partir de sus observaciones, siempre lúcidas y estimulantes, contenidas en su ensayo sobre La deshumanización del arte, debe entenderse como humano cuanto es fiel reflejo de la existencia cotidiana de las personas, en sus formas y contenidos vitales. En directa oposición a ello, todo proceso de deshumanización implicará negar o ignorar las manifestaciones, perfecciones y peripecias humanas ${ }^{28}$.

Entre los fenómenos apuntados por Ortega, para explicitar su teoría sobre la deshumanización del arte contemporáneo, estimo que poseen una proyección general para cualquier fenómeno deshumanizador, los que hacen referencia a la impopularidad, el antivitalismo y la intranscendencia.

Según se infiere de los argumentos de Ortega, en cualquier episodio deshumanizador, se produce un alejamiento de lo que es inteligible para la mayoría de las personas. Cuando las masas no entienden un fenómeno, éste se hace impopular, lo que significa que sus resortes no son los genéricamente humanos. El alejamiento o la impugnación de lo vital es otro de los rasgos que caracterizan la deshumanización. Si se extirpa la realidad vivida y se la

28 J. ORTEGA Y GASSET, La deshumanización del arte, en Obras Completas, Revista de Occidente \& Alianza Editorial, Madrid, 1983, vol., 3, pp. 353 ss. 
suplanta por formas abstractas, ideales o exotéricas, propias de un universo abstruso, se produce una fuga de lo humano. En esa tendencia no importa tanto el término ad quem, es decir, la entidad artificial a la que llega, sino en término a quo, el ámbito de vida que destruye. La deshumanización ostenta también, como síntoma caracterizador, la intrascendencia. Ortega hace notar que, frente a los afanes sociales y culturales que informan la existencia humana, el proceso deshumanizador supone una huida hacia la trivialización, que implica una evasión de la gravedad y el patetismo de lo humano ${ }^{29}$.

Las penetrantes observaciones de Ortega, pienso que pueden servir de pauta para la comprensión de los procesos deshumanizadores que dimanan del posthumanismo, si bien, en este ámbito se plantean con una intrínseca ambigüedad. Así, para el mayor número de integrantes de las sociedades tecnológicamente avanzadas, el universo tecnológico dista mucho de ser un escenario impopular. Las NT y las TIC y, en especial Internet, las redes sociales, los móviles..., se han instalado en la cotidianeidad cívica. El ordenador se ha convertido en un alter ego, en un partner constante y necesario para millones de personas, que precisan de la informática para el desarrollo habitual de su existencia. Como contrapunto, el diseño de la sociedad futura del proyecto posthumanista, sí es manifiestamente impopular, ya que propicia una fractura entre la élite de posthumanos, que encauzarán y aprovecharán los avances de la tecnociencia y la muchedumbre de humanos que quedarán marginados de esos eventuales beneficios.

La ambigüedad de esa tendencia deshumanizadora se advierte, quizás todavía con mayor intensidad, en lo que atañe al antivitalismo. La revolución tecnológica, desde sus inicios, no ha pretendido negar la vida humana, sino que ha querido imitar la vida, a través de unos entes artificiales que se asemejaran lo más posible a los seres humanos. La robótica no se presenta como una negación o un fenómeno hostil a la vida, sino como un complejo de entes tecnológicos que imitan, en la mayor proporción posible, a los seres humanos. En su lúcido diagnóstico, expresado en su libro, L’uomo artificiale, Vittorio Frosini indica que la tecnología ha pretendido elaborar un "hombre artificial", una especie de simia hominis, que intenta reproducir artificialmente los principales aspectos del comportamiento humano ${ }^{30}$. No huelga advertir que expresiones tales como "sistemas expertos" e "inteligencia artificial",

$29 \quad$ Ibid., pp. 354 ss., 364 ss. y 383 ss.

30 V. FROSINI, L'uomo artificiale. Etica e diritto nell era planetaria, Spirali, Milano, 1986, pp. 7 ss.

DERECHOS Y LIBERTADES

ISSN: 1133-0937

Número 44, Época II, enero 2021, pp. 17-40

DOI: https://doi.org/10.20318/dyl.2021.5848 
aluden a un intento de reproducción tecnológica de dos caracteres tan intrínsecamente humanos como son la experiencia y la inteligencia ${ }^{31}$ también, en esta esfera, el posthumanismo rompe con una valoración positiva de lo humano, al postular una posthumanidad, en la que se manifiestan rasgos anti vitalistas, como lo son sus pretensiones de cosificación, de sustituir el Internet de las personas por el Internet de las cosas, la suplantación de la vida orgánica basada en el carbono por la vida inorgánica a partir del silicio... Por último, resulta evidente que los miembros de la sociedad digital no consideran a las NT y las TIC, con sus logros y sus riesgos, como un fenómeno intrascendente. Tienen consciencia de que el presente y futuro de la sociedad tecnológica depende de un uso responsable de la tecnociencia. De Ahí, que los foros interdisciplinarios, donde se aúnan los esfuerzos de tecnólogos, sociólogos, economistas, juristas, filósofos..., se postule la Technogical Assessment o sea, la evaluación del impacto tecnológico en diversos sectores de la sociedad y la cultura. El proyecto posthumanista resulta especialmente insatisfactorio en este punto. Su designio deshumanizador no se plantea en términos de intrascendencia, pero sí en términos de irresponsabilidad, al legitimar la investigación y la experimentación tecnocientífica al margen de cualquier límite ético o jurídico.

La ambigüedad del discurso sobre la deshumanización tecnológica, con las consiguientes tensiones entre las posturas humanistas y posthumanistas, se comprueba nítidamente en la obra de quien es uno de los más afamados e informados exponentes del posthumanismo Yuval Noah Harari. Concluye Harari que los tres grandes rasgos de la concepción más dura del posthumanismo, el dataismo, se pueden cifrar en los postulados siguientes:

$1^{\circ}$ ) La concepción posthumanista de la ciencia afirma como dogma universal que los organismos son algoritmos y que la vida es procesamiento de datos;

$2^{\circ}$ ) La inteligencia se separa o desconecta de la conciencia;

$3^{\circ}$ ) Algoritmos sin conciencia, pero con una gran inteligencia, pronto podrán conocernos mejor que nosotros mismos. Esos asertos, que sintetizan la posición posthumanista, sugieren a Harari tres inte-

31 Vid., sobre ello, A.E, PÉREZ LUÑO, “Computerized Information Systems in General Jurisprudence and Philosophy of Law in Spain", en Expert Systems in Law. An International Conference on Law \& Artificial Intelligence (University of Bologna, May 3-5 1989), CIRFID, Bologna, 1989, pp. 1ss.; Id., "Expert Systems in Law. Premises for an Evaluation”, en el vol., col., a cargo de C. Ciampi, F. Socci Natali y G. Taddei Elmi, Verso un sistema esperto giuridico integrale, Cedam, Padova, 1996, vol. II, pp. 257 ss. 
rrogantes básicos con los que finaliza su exposición: “1) ¿Son en verdad los organismos sólo algoritmos y es en verdad la vida sólo procesamiento de datos? 2) ¿Qué es más valioso la inteligencia o la conciencia? 3) ¿Qué le ocurrirá a la sociedad, a la política y a la vida cotidiana, cuando algoritmos no conscientes, pero muy inteligentes, nos conozcan mejor que nosotros mismos?" 32 .

Creo necesario hacer notar que, en el pensamiento y en el planteamiento de Harari, se deslizan unas ambigüedades insoslayables. A lo largo de toda su obra reitera la afirmación de que no pretende hacer una profecía, sino hacerse cargo y dar cuenta de los desarrollos presentes y futuros de la tecnociencia, a partir del diseño posthumanista. Ahora bien, esa pretendida actitud neutral de observador y cronista, se ve desmentida, porque a lo largo de sus reflexiones, Harari hace implícitamente suyas las tesis del posthumanismo y, en la mayor parte de las ocasiones, las considera como verdades técnico-científicas irrefutables e irreversibles. Es cierto que Harari reconoce la conciencia como el último baluarte, todavía no expugnado por la IA, y así reconoce que, hasta el momento no parece que los ordenadores puedan tener conciencia y experimentar emociones y sensaciones. En los últimos años, se ha producido un inmenso avance en el desarrollo de la IA, pero el avance en la elaboración de una conciencia artificial ha sido nulo, pero tras haber admitido esto, Harari reconoce que los seres humanos están perdiendo su valor, en términos de conciencia, porque la inteligencia, separada de la conciencia, es capaz de realizar operaciones que antes se hallaban reservadas a una inteligencia consciente, tales como: jugar a la ajedrez, diagnosticar enfermedades, conducir un automóvil o realizar una pesquisa policial para perseguir un delito. En la actualidad, este tipo de operaciones, según Harari, pueden ser desarrolladas por una IA, independizada de la conciencia, mucho mejor y con mayor eficacia que las que pueden realizar los seres humanos ${ }^{33}$.

Gran parte del libro de Harari se halla dedicado a mostrar que las religiones, las ideologías políticas, en particular el liberalismo y el comunismo, y la tradición cultural humanista, constituyen anacronismos inoperantes e incompatibles con la evolución tecnocientífica de nuestro tiempo. No obstante, esos movimientos son los que podrían ofrecer un fundamento axiológico a la conciencia. Harari no ofrece ninguna alternativa ética que pudiera sustentar a la conciencia, ante su actual asedio tecnocientífico. Por ello, de forma implí-

32 Y. N. HARARI, Homo Deus: Breve historia del mañana, cit., pp. 430-431.

33 Ibid., pp. 341 ss. 
cita, Harari está aceptando que no existe ninguna posibilidad de que la conciencia dirija a la inteligencia y que la inteligencia humana dirija y controle a la IA en la organización del mundo y de la vida.

\section{CONCLUSIÓN: EL POSTHUMANISMO NO ES UN HUMANISMO}

Al enfilar el último tramo de estas reflexiones, el itinerario teórico trazado hasta aquí permite dilucidar el significado lingüístico del término "posthumanismo". Debe indicarse, al respecto, que el prefijo "post", que se integra en la expresión "posthumanismo", puede asumir dos significados diferentes: puede aludir a la sucesión cronológica o al perfeccionamiento de las concepciones o movimientos que le preceden; o bien, expresar la abolición de los mismos.

De cuanto hasta aquí se lleva dicho, se desprende que el posthumanismo, asume la segunda acepción indicada. Por ello, el posthumanismo no implica la mejora, perfeccionamiento o actualización del legado humanista, sino que supone su negación, abolición o suplantación. El posthumanismo, por tanto, entraña un antihumanismo, por lo que se sitúa frente a lo que ha sido una de las principales conquistas históricas de la tradición humanista: los derechos humanos. Por ello, aludir a una generación de derechos humanos posthumanistas, o lo que es lo mismo, antihumanistas implica una evidente contradictio in terminis ${ }^{34}$.

La negación posthumanista de los derechos y libertades puede conducir a la posibilidad ominosa de que determinadas decisiones, fundamentales para la vida, sean sustraídas a la voluntad autónoma y libre de los seres humanos, para ser asumidas por el poder impersonal y difuso de las cosas. Dicha posibilidad deja en la penumbra a las fuerzas o poderes que pueden controlar la autonomía de las cosas y la robótica, en función de sus propios intereses.

Hace ya algunos años, Jürgen Habermas en su lúcida obra: Ciencia y técnica como ideología, denunció la pretensión tecnocrática de presentar determinado tipo de conocimientos y propuestas como postulados tecnocientíficos, cuando en realidad, ocultan opciones prácticas e intereses. La ideología tecnocrática trata de sustraer al debate científico y político cuestiones

34 A.E. PÉREZ LUÑO, “Las generaciones de derechos humanos ante el desafío posthumanista", cit., pp. 149 ss. 
que interesan a la generalidad de los ciudadanos y que, por tanto, deben permitir su libre discusión. Los tecnócratas incurren en la manipulación ideológica consistente en ocultar sus intereses particulares, para presentarlos como teorías tecnocientíficas, cuando en realidad suponen meras propuestas ideológicas ${ }^{35}$. Jürgen Habermas concluye su lúcida reflexión, afirmando que: "al desafío de la técnica, no se le puede responder sólo con la técnica" ${ }^{36}$.

Los principales argumentos posthumanistas se presentan, en la actualidad, como verdades tecnocientíficas irrefutables e inexorables. No obstante, un análisis crítico de esas propuestas revela que ese discurso responde a la pretensión ideológica de escamotear las grandes elecciones y decisiones sobre el presente y el futuro de la condición humana y del desarrollo tecnológico al debate político democrático. Tiene razón Stefano Rodotà cuando, tal como se ha indicado anteriormente, se pregunta, si las transformaciones previstas y auspiciadas por el posthumanismo, se plantean en nombre del beneficio económico o del interés de las personas ${ }^{37}$. Para responder a estos retos, que afectan a la humanidad en su conjunto, no debe acudirse a la IA, sino a las opciones de la sociedad política.

El carácter ideológico de las propuestas posthumanistas se evidencia también cuando, a través de ellas, se propugna expropiar de la decisión colectiva ética y política, las cuestiones vitales de toda sociedad, como la educación, la sanidad, el medio ambiente o la pobreza. Los poderes que apoyan y financian la investigación tecnocientífica, no son anónimos ni neutrales, se trata de personas entidades o corporaciones reales y concretas, con intereses e ideologías fácilmente comprobables, que no pueden, ni deben, eludir su responsabilidad social y política.

Las tesis posthumanistas pretenden relegar la cultura humanista y considerarla como una experiencia periclitada y conclusa. Desde las premisas posthumanistas se pretende desconocer que el proyecto jurídico-político humanista es todavía una promesa incumplida para amplios sectores de nuestro mundo, que no se han emancipado de la ignorancia, del hambre o de la opresión. Se produce así la situación paradójica de que, mientras se está

35 J.HABERMAS, Technik und Wissenschaft als Ideologie, Suhrkamp, Frankfurt a.M., 1968, pp. 27 ss. (existe trad. cast. Tecnos, Madrid, 1984); vid., también su obra, El futuro de la naturaleza humana ¿Hacia una eugenesia liberal?, cit., pp. 44 ss.

36 J. HABERMAS, Technik und Wissenschaft als Ideologie, cit., p. 118.

37 S. RODOTÀ, “Del ser humano al posthumano”, cit., pp. 92 ss.

DERECHOS Y LIBERTADES

ISSN: $1133-0937$

Número 44, Época II, enero 2021, pp. 17-40

DOI: https://doi.org/10.20318/dyl.2021.5848 
reclamando un proyecto posthumanista, grandes sectores de la población mundial se hallan condenados a una condición de infrahumanidad ${ }^{38}$.

El proyecto posthumanista y sus previsiones para el porvenir, pueden parecer un sarcasmo para los millones de personas golpeadas en su calidad de vida y en el desarrollo de su cotidianeidad por el coronavirus. Un ente microscópico como el COVID-19 ha puesto de manifiesto la vulnerabilidad de la sociedad digital. En el momento actual, tras la imagen prepotente y avasalladora de un Homo Deus, dominador absoluto y definitivo de todas las fuerzas y fenómenos de la naturaleza a través de la tecnociencia, aparece la sombra inquietante del agustiniano Homo fallens. Mérito del humanismo es que, todavía hoy, representa un motivo de equilibrio superador de esas dos visiones contrapuestas de la condición humana. El humanismo denuncia y cuestiona la pretensión posthumanista de abolir los valores de su tradición cultural y desenmascara el mito de una nueva Arcadia fundada en la IA. El Homo Deus se muestra como una divinidad harto frágil e insuficiente. No menos opuesta a la cultura humanista resulta la imagen de una humanidad caída, incapaz de encauzar a través de la experiencia y de la razón su propio destino y el uso adecuado de la tecnociencia. El humanismo se muestra siempre abierto a admitir y promover los avances científicos y tecnológicos que puedan contribuir a una mejora de la calidad de la vida humana: el humanismo apuesta, decididamente, por un progreso tecnológico presidido siempre por la racionalidad y la responsabilidad.

No parece juicioso dudar de que la tecnociencia ha contribuido a responder al desafío de la pandemia con mucha mayor eficacia y celeridad de cuanto pudieran haberlo hecho las sociedades del pasado. Los avances de la investigación médica, los nuevos medios y equipos terapéuticos, las posibilidades ofrecidas por las TIC para una comunicación, en tiempo real, entre todos los Gobiernos del mundo, entre éstos y sus ciudadanos y entre los ciudadanos entre sí, han permitido afrontar esa crisis planetaria decisivamente mejor que si no se hubiera contado con esos avances. Es fácil imaginar, por poner un ejemplo, la compañía y el apoyo que, para millones de personas, ha supuesto el poder contar con la TV, la radio, los móviles y el acceso a

38 Sobre la persistencia y la necesidad de mantener vivo el proyecto cultural humanista de la modernidad, que todavía no ha sido plenamente realizado y que, por tanto, no puede considerarse superado, vid., el ensayo de J. HABERMAS, "La modernidad: un proyecto inacabado", en su vol., Ensayos políticos, trad. cast. R. García Cotarelo, Península, Barcelona, 1988 , pp. 279 ss. 
Internet. Disponer de esos medios tecnológicos ha paliado la situación de forzoso aislamiento y confinamiento padecido por la mayor parte de habitantes del planeta. La quiebra que para la calidad de la vida humana representa la imposibilidad de mantener relaciones personales, sin trabas, se ha visto mitigada por la posibilidad de una relación virtual. No huelga tampoco soslayar que la comunicación ciberespacial ha propiciado la creación de redes de solidaridad entre un gran número de cibernautas, lo que permite augurar un reforzamiento de valores comunitarios y, en particular, de aquellos que informan la cultura humanista. Como contrapartida, inherente a gran parte de los progresos tecnocientíficos, se ha suscitado una cierta ambivalencia: esos logros y ventajas se han hallado contrapuntados por un efecto multiplicador de las sensaciones de confusión, alarma y ansiedad, provocadas por la invasión en la Red de todo tipo de postverdades y de fake news.

Quien fue el creador de la cibernética, Norbert Wiener, en un trabajo cuya primera versión fue publicada al promediar el pasado siglo, afirmó que la cibernética era la ciencia de la comunicación y el control entre los seres vivos y las máquinas. Reclamó, al propio tiempo, una utilización responsable de esa nueva versión de la ciencia y la tecnología, de forma que propiciara un uso humano de los seres humanos y advirtió, con lucidez premonitoria, que el tiempo apremiaba y que era necesario elegir entre el bien y el $\mathrm{mal}^{39}$. Al concluir esta reflexión y, tomando en préstamo la afirmación de Wiener, pienso que el bien sigue estando representado por los valores y derechos ligados a la tradición cultural humanista, mientras que el mal subyace a determinadas propuestas posthumanistas, sobre cuyos riesgos y falacias he intentado advertir en este ensayo.

Antonio EnRiQue Pérez LuÑo Departamento de Filosofía del Derecho Facultad de Derecho c/ Enramadilla, 18 41018 Sevilla e-mail:aperez3@us.es

39 N. WIENER, The Human Use of Human Beings. Cybernetics and Society, con una nueva Introducción a cargo de S. J. Heims, Free Association Books, London, 1989, pp. 216 ss.

DERECHOS Y LIBERTADES

ISSN: 1133-0937

Número 44, Época II, enero 2021, pp. 17-40

DOI: https://doi.org/10.20318/dyl.2021.5848 